\title{
METHODS AND APPLICATIONS
}

\section{Solution NMR resonance assignment strategies for $\beta$-barrel membrane proteins}

\author{
Daniel A. Fox and Linda Columbus* \\ Department of Chemistry, University of Virginia, Charlottesville, Virginia 22904
}

Received 13 March 2013; Revised 17 May 2013; Accepted 18 May 2013

DOI: $10.1002 /$ pro.2291

Published online 10 June 2013 proteinscience.org

\begin{abstract}
Membrane proteins in detergent micelles are large and dynamic complexes that present challenges for solution NMR investigations such as spectral overlap and line broadening. In this study, multiple methods are introduced to facilitate resonance assignment of $\beta$-barrel membrane proteins using $\mathrm{Opa}_{60}$ from Neisseria gonorrhoeae as a model system. $\mathrm{Opa}_{60}$ is an eight-stranded $\beta$-barrel with long extracellular loops ( $63 \%$ of the protein) that engage host receptors and induce engulfment of the bacterium. The NMR spectra of Opa 60 in detergent micelles exhibits significant spectral overlap and resonances corresponding to the loop regions had variable line widths, which interfered with a complete assignment of the protein. To assign the $\beta$-barrel residues, trypsin cleavage was used to remove much of the extracellular loops while preserving the detergent solubilized $\beta$-barrel. The removal of the loop resonances significantly improved the assignment of the Opa $_{60} \beta$-barrel region $(97 \%$ of the resonances corresponding to the $\beta$-barrel and periplasmic turns were assigned). For the loop resonance assignments, two strategies were implemented; modulating temperature and synthetic peptides. Lowering the temperature broadened many peaks beyond detection and simplified the spectra to only the most dynamic regions of the loops facilitating 27 loop resonances to be assigned. To further assign functionally important and unstructured regions of the extracellular loops, a synthetic 20 amino acid peptide was synthesized and had nearly complete spectral overlap with the full-length protein allowing 17 loop resonances to be assigned. Collectively, these strategies are effective tools that may accelerate solution NMR structure determination of $\boldsymbol{\beta}$-barrel membrane proteins.
\end{abstract}

Keywords: outer membrane protein; NMR; assignments; $\beta$-barrel membrane protein

Introduction

Solution NMR structure determination of membrane proteins allows the investigation of membrane

Additional Supporting Information may be found in the online version of this article.

Grant sponsor: National Institutes of Health; Grant number: R01GM087828; Grant sponsor: Jeffress Memorial Trust, Grant sponsor: Research Corporation for Scientific Advancement.

${ }^{*}$ Correspondence to: Linda Columbus, Department of Chemistry, University of Virginia, Charlottesville, VA 22904. E-mail: columbus@virginia.edu protein dynamics and their role in protein function. ${ }^{1-6}$ However, the number of high-resolution polytopic membrane protein structures is limited. To date, there are six NMR solution structures of $\beta$-barrel membrane proteins ${ }^{1-6}$ (compared to the 89 unique $\beta$-barrel structures deposited in the Protein Data Bank), all except for OprH have corresponding X-ray crystal structures. ${ }^{7-12}$ The first $\beta$-barrel membrane protein structure determined with solution NMR was in $2001^{4}$ and the latest structure was determined in $2011^{3}$ yielding an average of 0.6 structures a year. The dearth of solution NMR membrane 
protein structures is likely due to the difficulty of obtaining quality NMR spectra, which interferes with assigning the resonances and obtaining quality structural restraints.

There have been many NMR developments to overcome some of the challenges in studying large complexes including membrane proteins. Deuteration $^{13}$ and transverse relaxation optimized spectroscopy (TROSY) pulse sequences ${ }^{14}$ circumvent relaxation effects that hinder NMR spectral quality of larger biomolecules ( $>25 \mathrm{kDa})$. In addition, assignment of resonances in regions with significant spectral overlap can be addressed with specific amino acid labeling ${ }^{15-17}$ as well as compensating for the loss of proton-proton distance restraints due to deuteration. ${ }^{18,19}$ Other methods, such as residual dipolar couplings ${ }^{20}$ and paramagnetic relaxation enhancement, ${ }^{21}$ have provided additional structural restraints crucial for large $\alpha$-helical proteins (e.g., $\alpha$-helical membrane proteins in detergent micelles). With these advances, six solution NMR $\beta$-barrel membrane protein structures (varying in the number of $\beta$-strands (8-19) and molecular weight (16-31 $\mathrm{kDa})$ have been determined. ${ }^{1-6}$

In this study, the difficulties of assigning $\mathrm{Opa}_{60}$, a $\beta$-barrel membrane protein from Neisseria gonorrhoeae, ${ }^{22}$ are outlined and strategies for circumventing these challenges are demonstrated. $\mathrm{Opa}_{60}$ is a putative eight-stranded $\beta$-barrel with four extracellular loops, which comprise approximately $63 \%$ of the protein. ${ }^{23}$ The two main difficulties in assigning $\mathrm{Opa}_{60}$ were: (1) the abundant loop resonances occluded some of the $\beta$-barrel resonances, which are much less intense than the loop resonances and (2) the loops have variable dynamics with some resonances sharp and intense, while others are significantly line broadened. In addition to previously established methods such as specific amino acid labeling, several new strategies were used to assign the different regions of $\mathrm{Opa}_{60}$. The $\beta$-barrel resonances $(97 \%)$ were assigned by cleaving the extracellular loops with trypsin, which improved spectral quality and allowed resonances occluded by the loops to be observed. Assignment of loop resonances (24\%) required both the manipulation of temperature and a synthetic peptide. Overall, 49\% of $\mathrm{Opa}_{60}$ was assigned and sufficient for structure calculations of the full-length $\mathrm{Opa}_{60}$.

\section{Results and Discussion}

\section{Challenges encountered in NMR investigations of $\mathrm{Opa}_{60}$}

The optimized solution condition yielded quality ${ }^{15} \mathrm{~N}$, ${ }^{1} \mathrm{H}-\mathrm{HSQC}$ (TROSY versions of pulse sequences were used throughout) spectra of $\mathrm{Opa}_{60}$ with approximately 225 unique resonances observed, with many downfield resonances $(>8.5 \mathrm{ppm})$ typically associated with $\beta$-strands. Elevated temperature $\left(40^{\circ} \mathrm{C}\right)$ was required to observe resonances corresponding to the $\beta$-barrel region. Despite the observation of a number of peaks that correspond to the $\beta$-barrel, the assignment was hindered due to spectral overlap with the more intense loop resonances. In addition, the high temperature necessary to observe the $\beta$-barrel resonances resulted in line broadening of a subset of the loop resonances, which interfered with assigning loop sequences. As a result, an assignment of $\mathrm{Opa}_{60}$ proved to be unobtainable from a single condition.

\section{Proteolysis facilitates assignment of $\beta$-barrel}

In order to observe the less intense $\beta$-barrel peaks in the crowded region of the spectrum, a protease was used to cleave the extracellular loops from the protein-detergent complex. Based on the amino acid sequence, the predicted topology of the $\beta$-barrel, and the inaccessibility of the $\beta$-barrel to proteases, ${ }^{24}$ trypsin is predicted to remove 94 residues [Fig. 1(A) and Supporting Information Fig. S1, red regions]. The remaining micelle-protected $\beta$-barrel would have an approximate molecular weight of $15 \mathrm{kDa}$ ( $\sim 30-35 \mathrm{kDa}$ including the micelle). The $\mathrm{Opa}_{60}$ $\beta$-barrel remains intact after proteolysis even upon boiling in sodium dodecyl sulfate (SDS) loading buffer (Fig. 2) despite being composed of five transmembrane fragments [topology shown in Fig. 1(A)]. The ${ }^{15} \mathrm{~N},{ }^{1} \mathrm{H}-\mathrm{HSQC}$ of the trypsin-cleaved $\mathrm{Opa}_{60}$ results in 147 unique resonances with approximately equal intensities that overlap with the full-length $\mathrm{Opa}_{60}$ spectrum [Fig. 1(B)]. In addition to reduction of spectral overlap, significant improvement was observed in the 3D spectral quality (Supporting Information Fig. S2). Thus, using this methodology $97 \%$ of the transmembrane $\beta$-barrel and periplasmic turns of full-length $\mathrm{Opa}_{60}$ was assigned (Supporting Information Fig. S3).

To determine whether this method is generally applicable to NMR investigations of $\beta$-barrel structures, two other proteins, $\mathrm{Opa}_{50}$ and $\mathrm{OprH}$, were investigated. $\mathrm{Opa}_{50}$ and $\mathrm{Opa}_{60}$ differ by one amino acid in the $\beta$-barrel region (Supporting Information Fig. S1); however, three of the extracellular loops differ significantly in sequence. The trypsin-treated $\mathrm{Opa}_{50}$, as compared to the full-length protein, migrates on an SDS-PAGE (polyacrylamide gel electrophoresis) gel similarly to $\mathrm{Opa}_{60}$ and indicates the $\beta$-barrel is maintained after cleavage even after boiling in SDS loading buffer (Fig. 2). The ${ }^{15} \mathrm{~N},{ }^{1} \mathrm{H}$ HSQC spectrum of $\mathrm{Opa}_{50}$ after trypsin cleavage overlaps with the corresponding peaks of the spectrum of the full-length protein [Fig. 1(C)]. The overlap with the full-length is essential for structure determination because the NOESY spectra of the full-length should be used for the final structure calculation. In addition, ${ }^{15} \mathrm{~N},{ }^{1} \mathrm{H}-\mathrm{HSQC}$ of the trypsin treated $\mathrm{Opa}_{50}$ and $\mathrm{Opa}_{60}$ are nearly superimposable, 

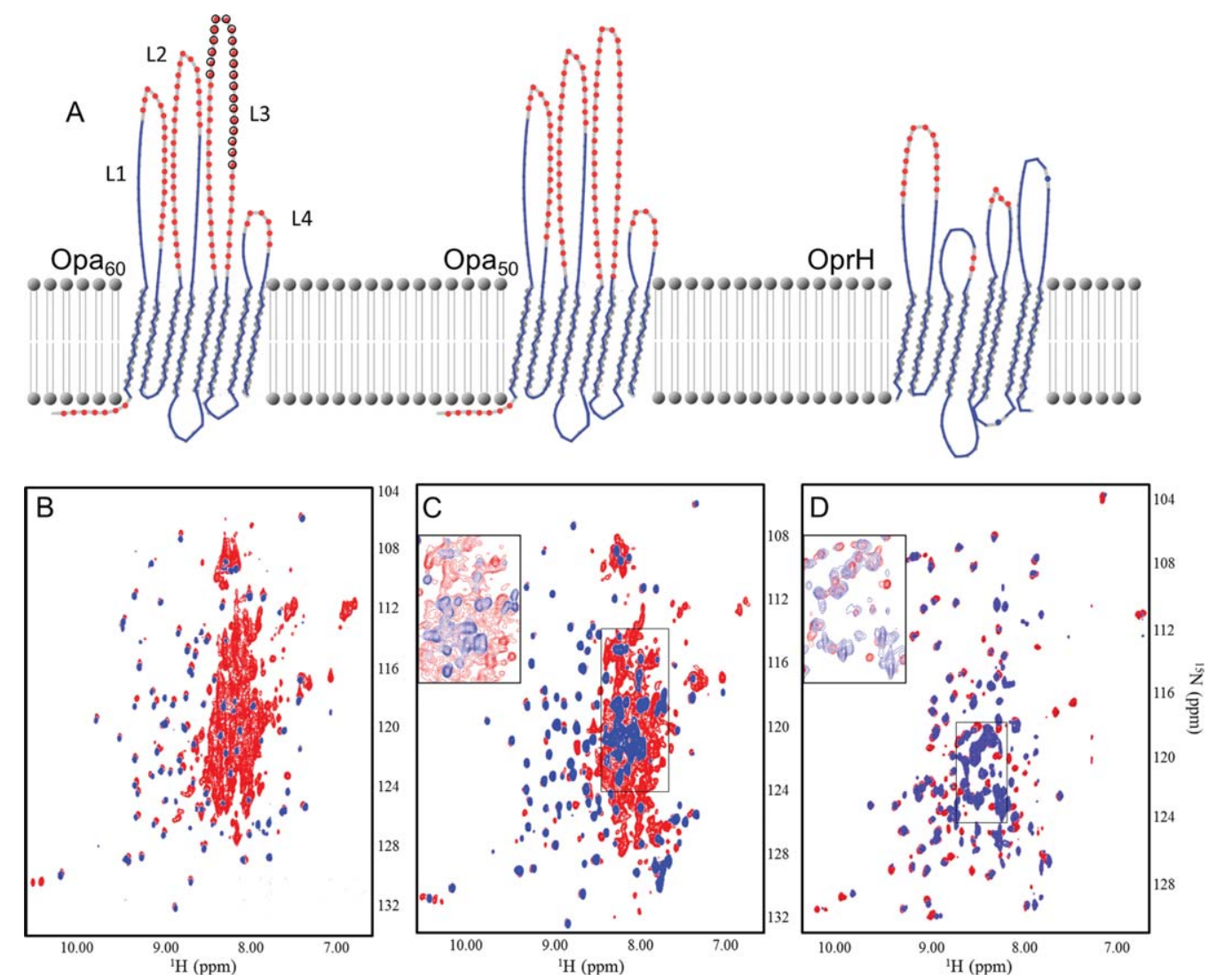

Figure 1. Trypsin cleavage of $\beta$-barrel membrane proteins. A: Topology diagram of $\mathrm{Opa}_{60}$, Opa lular residues predicted to be removed with trypsin colored red and the remaining residues colored in blue. The outlined red circles indicate the residues that were selected for the synthetic peptide. Extracelular loops 1-4 are labeled L1-L4. A sequence alignment of the three proteins is provided in Supporting Information Figure S1. B-D: Full-length (red) and trypsin-treated (blue) ${ }^{15} \mathrm{~N},{ }^{1} \mathrm{H}-\mathrm{HSQC}$ spectra of ${ }^{2} \mathrm{H},{ }^{15} \mathrm{~N}$-labeled Opa 60 (B), Opa 50 (C), and OprH (D).

indicating that the $\beta$-barrel structure of the different Opa proteins is likely identical (Supporting Information Fig. S4).

OprH has the longest extracellular loop (29 amino acids) of the six $\beta$-barrel membrane protein structures determined with $\mathrm{NMR}^{3}$ and, thus, was used to investigate the general applicability of the trypsin methodology for $\beta$-barrel membrane protein NMR resonance assignment. As both the ${ }^{15} \mathrm{~N}$, ${ }^{1} \mathrm{H}-\mathrm{HSQC}$ spectra [Fig. 1(D)] and SDS-PAGE mobility (Fig. 2) indicate, the $\beta$-barrel remains unperturbed after trypsin cleavage. However, there were a few notable differences compared to the Opa proteins. Upon boiling in SDS loading buffer, the OprH $\beta$-barrel did not remain intact (Fig. 2) implying that the fold may be less stable than the Opa proteins. After cleavage, broadening of some extracellular loop resonances is observed [Fig. 1(D) inset] in OprH, which was not observed for $\mathrm{Opa}_{50}$ or $\mathrm{Opa}_{60}$ [Fig. 1(B, inset $C)$ ]. In contrast to the Opa proteins, cleavage of three of the OprH extracellular loops leaves most of the loop residues still attached to the $\beta$-barrel, which may alter the dynamics of the loops and result in the observed line broadening. Thus, the proteolytic cleavage may be generally applicable to $\beta$-barrel membrane proteins with variable overall stabilities; however, significant cleavage (which can be predicted from amino acid sequence) should be achieved for optimal results.

\section{Facilitating loop assignments: temperature}

All solution NMR $\beta$-barrel membrane protein structures determined to date have contained relatively

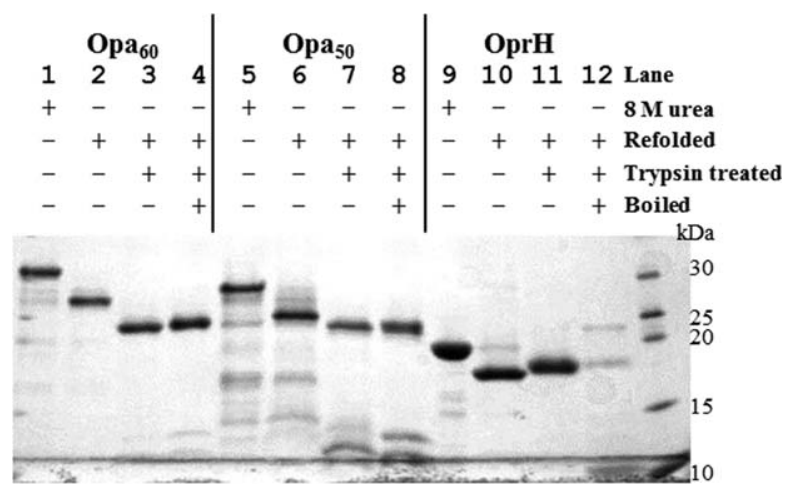

Figure 2. SDS-PAGE of Opa 60 (Lanes 1-4), Opa 50 (Lanes 58), and OprH (Lanes 9-12) unfolded in $8 M$ urea, folded via rapid dilution into detergent micelles, cleaved with trypsin, and boiled after trypsin cleavage. 


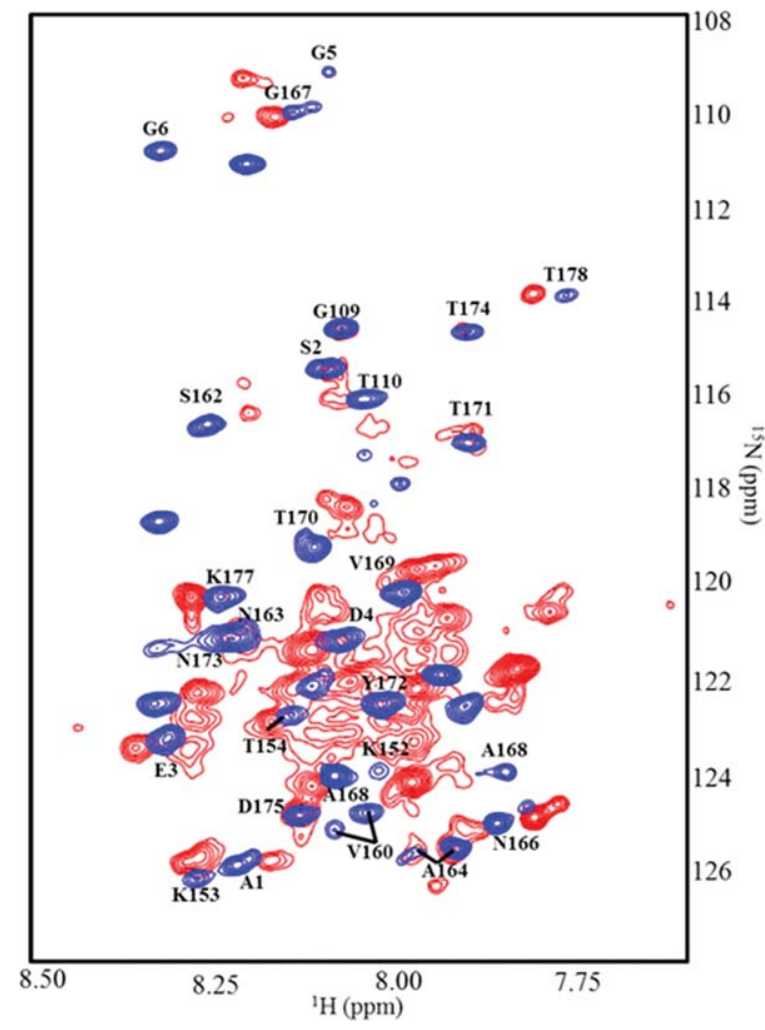

Figure 3. ${ }^{15} \mathrm{~N},{ }^{1} \mathrm{H}-\mathrm{HSQC}$ spectra of ${ }^{1} \mathrm{H},{ }^{15} \mathrm{~N}$-labeled $\mathrm{Opa}_{60}$ recorded at $40^{\circ} \mathrm{C}$ (red) and $10^{\circ} \mathrm{C}$ (blue). Backbone resonances assigned at low temperatures are labeled.

short extracellular loops [the longest loop that of OprH containing 29 amino acid; Fig. 1(A)]; thus, spectral overlap and line broadening from loop resonances did not hinder the assignment of the majority of the protein. $\mathrm{Opa}_{60}$ has three long extracellular loops with two loops composed of over 40 amino acids. The loops are unstructured based on circular dichroism (data not shown), amide proton chemical shift, and the ${ }^{15} \mathrm{~N}$ edited NOESY spectrum (data not shown). NMR relaxation data suggests some loop regions are mobile on the nanosecond timescale ( $\tau \approx 2-5 \mathrm{~ns}$ compared to $\tau \approx 20 \mathrm{~ns}$ for the $\beta$-barrel (and associated detergent, data not shown). A subset of loop resonances exhibit significant line broadening at $40^{\circ} \mathrm{C}$ (Fig. 3; red spectrum) and could not be assigned. At lower temperatures, the intensity of the $\beta$-barrel peaks decrease beyond detection and the line widths of a population of loop resonances decrease. Of the 149 potentially observable resonances from the extracellular loops and N-terminus, 34 disperse well-defined resonances are observed (Fig. 3; blue spectrum). As the temperature decreases, the overall tumbling of the proteindetergent complex slows, causing the $\beta$-barrel peaks (and likely many of the loop residues near the $\beta$-barrel) to broaden beyond detection. However, the loop regions most extended from the micelle fluctuate more rapidly than the $\beta$-barrel-micelle complex and, therefore, may be observed at lower temperatures. Using a series of $3 \mathrm{D}$ NMR experiments, the amide proton, nitrogen, and $\alpha$-carbon were assigned for 27 of the 34 observed resonances (corresponding to residues $1-6$ in the N-terminus; $109-110$ in loop 2; 152$154,160,162-164,166-175$, and 177-178 in loop 3). A series of ${ }^{15} \mathrm{~N},{ }^{1} \mathrm{H}-\mathrm{HSQC}$ spectra were recorded at 10 , 20,30 , and $40^{\circ} \mathrm{C}$ and the peaks were tracked through each spectrum in order to correlate the low temperature assignments to the assignment of the full length $\mathrm{Opa}_{60}$ at $40^{\circ} \mathrm{C}$.

\section{Facilitating loop assignments: synthetic peptide}

After observing that the most extended regions of the loops lacked secondary structure, unique individual peptides were considered. ${ }^{25}$ Different peptide sequences were selected based on the biological relevance (two regions in loops 2 and 3 are identified to be important in engaging host receptors ${ }^{26}$ ), solubility, and amino acid composition. There are several hydrophobic residues in the loop regions, which dramatically affected the GRAVY value ${ }^{27}$ and likely the solubility of many peptides that were considered. The peptide selected corresponded to residues 159178 in extracellular loop 3 [Fig. 1(A)] and had a GRAVY value ${ }^{27}$ of -0.835 . Near complete spectral overlap was observed in the ${ }^{15} \mathrm{~N},{ }^{1} \mathrm{H}-\mathrm{HSQC}$ of the peptide and full-length Opa 60 [Figs. 4 and 5(A)].

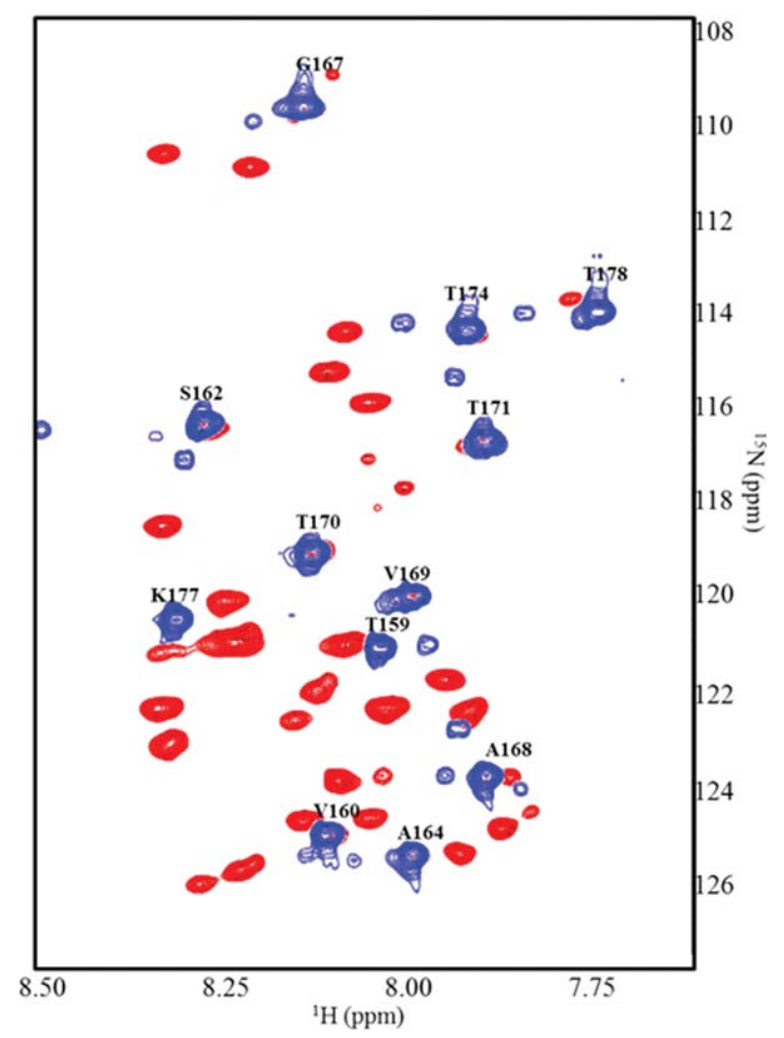

Figure 4. An overlay of the ${ }^{15} \mathrm{~N},{ }^{1} \mathrm{H}-\mathrm{HSQC}$ spectrum of the synthetic peptide $T^{*}-V^{*}-P-S^{*}-N-A^{*}-P-N-G^{*}-A^{*}-V^{*}-T^{*}-T^{*}-Y-N-$ $T^{*}-D-P-K^{*}-T^{*}\left({ }^{*}\right.$ denotes ${ }^{15} \mathrm{~N}$ isotope labeling) corresponding to a the hypervariable region of loop 3 [Fig. 1(A)] and the ${ }^{15} \mathrm{~N}$, ${ }^{1} \mathrm{H}$-HSQC spectrum of ${ }^{1} \mathrm{H},{ }^{15} \mathrm{~N}$ labeled Opa 60 (full-length) recorded at $10^{\circ} \mathrm{C}$. 
A

B
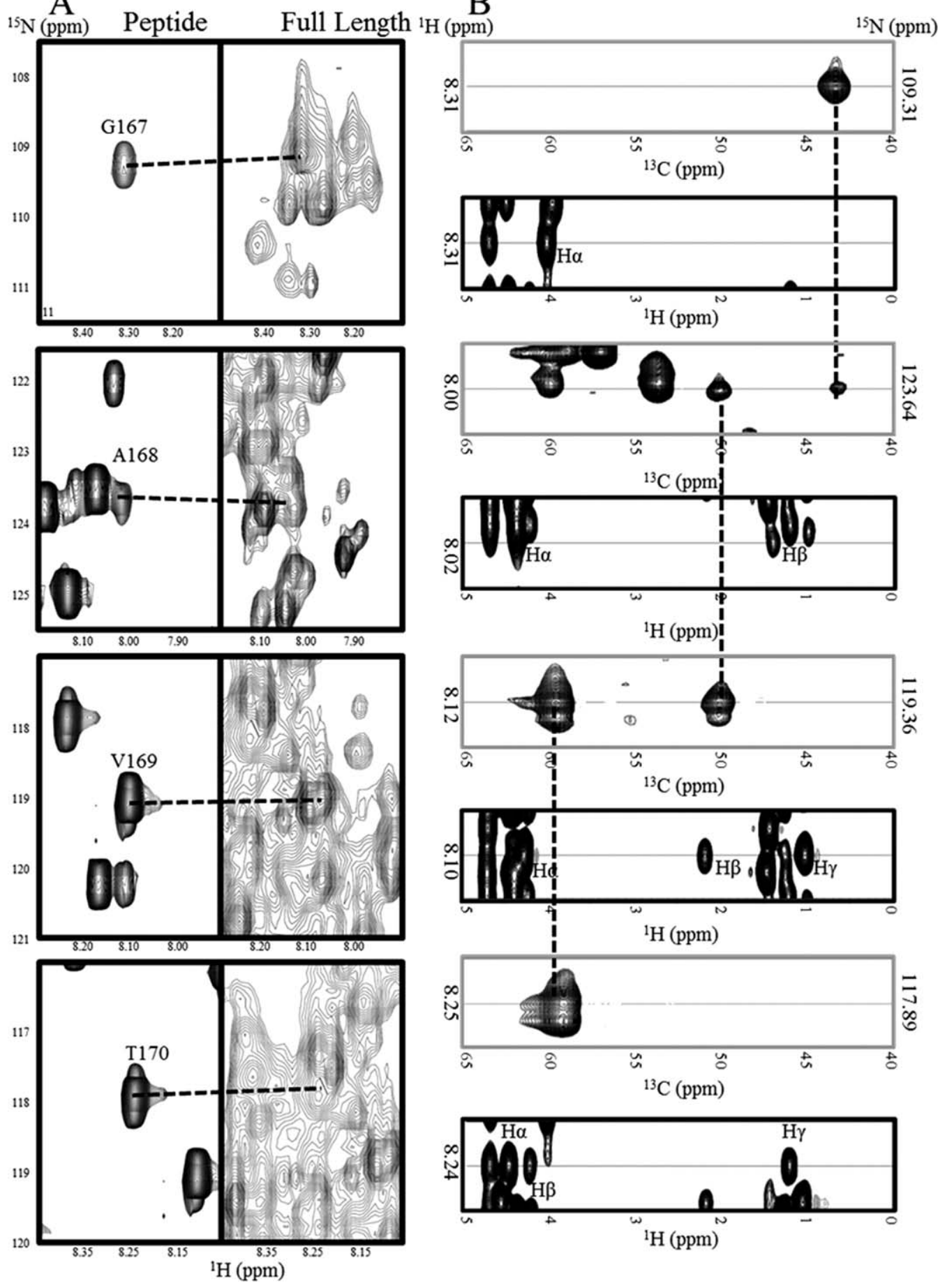

Figure 5. Backbone assignment of loop resonances using a synthetic peptide. A: ${ }^{15} \mathrm{~N},{ }^{1} \mathrm{H}-\mathrm{HSQC}$ spectra were recorded for both peptide and $\mathrm{Opa}_{60}$ (zoomed in regions of specific resonances are shown) and based on overlap (indicated by black dashed line) identical spins in the full length and peptide were identified. B: The homonuclear $2 \mathrm{D}{ }^{15} \mathrm{~N}$-edited ${ }^{1} \mathrm{H},{ }^{1} \mathrm{H}$-TOCSY strips (black strips) identified side chain spin systems and compared to the HNCA strips (gray strips) to obtain the sequential assignment. Connectivity between $\mathrm{C}_{\alpha, i}$ and $\mathrm{C}_{\alpha, i-1}$ resonances are shown with a dashed black line.

Only twelve residues were ${ }^{15} \mathrm{~N}$ labeled, but through both heteronuclear and homonuclear NMR experiments the assignment of the peptide resonances and, the full-length by comparison, could be assigned. The amino acid ${ }^{1} \mathrm{H}$ and ${ }^{15} \mathrm{~N}$ spin systems were identified with ${ }^{1} \mathrm{H},{ }^{1} \mathrm{H}$-COSY, ${ }^{1} \mathrm{H},{ }^{1} \mathrm{H}$-TOCSY, and ${ }^{15} \mathrm{~N}$-edited versions of each. Using the spin system identifications from the TOCSY spectrum of the peptide, the amino acid type for HNCA strips was identified and, thus, sequentially assigned [Fig. 5(B)]. The sequential assignment of the peptide could then be transferred to the full length $3 \mathrm{D}$ spectra (based on spectral overlap in the ${ }^{15} \mathrm{~N},{ }^{1} \mathrm{H}-\mathrm{HSQC}$ spectra) and verified with the HNCA of the full 
length protein. Given the amount of spectral overlap, amino acid composition, and chemical shift degeneracy in this loop region, previous attempts to assign the resonances proved too difficult prior to the peptide comparison.

\section{Conclusion}

The results presented provide specific strategies for assigning resonances of $\beta$-barrel membrane proteins in an effort to accelerate solution NMR structure determination. The difficulty for $\beta$-barrel membrane proteins is exemplified with the Opa proteins in comparison to previously determined $\beta$-barrel membrane proteins solution NMR structures. The Opa proteins have two domains with very different dynamical properties (the unstructured extracellular loops and the membrane embedded $\beta$-barrel). An approach was used that would isolate these two domains such that they could be investigated independently. Protease cleavage was the most effective way to assign the $\beta$-barrel resonances and as observed in the ${ }^{15} \mathrm{~N},{ }^{1} \mathrm{H}-\mathrm{HSQC}$ spectra [Fig. 1(B-D)], protease cleavage for three different $\beta$-barrel proteins did not affect the global fold of the $\beta$-barrel. To assign the loops, temperature was used to modulate the dynamics of the loops and provided conditions in which loop resonances could be assigned. Temperature should be sought first before attempting the third strategy of synthetic peptides for two reasons (1) cost and (2) to provide direction in the peptide design that would be most helpful in obtaining the most assignment coverage. The peptide strategy is likely only helpful for assigning unstructured regions. Alternatively, proteolytic cleavage sites can be engineered in specific extracellular loops to reduce spectral crowding for assignment of other loop resonances or in cases where loop cleavage destabilizes the protein. In summary, the strategies described here are effective tools in a much needed toolbox for solution NMR structure determination of membrane proteins.

\section{Materials and Methods}

\section{Expression and purification of $\mathrm{Opa}_{60}$ and $\mathrm{Opa}_{50}$}

Protocols for expression and purification were previously published. ${ }^{28}$ Briefly, the gene for $\mathrm{Opa}_{60}$ and $\mathrm{Opa}_{50}$ were sub-cloned into $\mathrm{pET} 28 \mathrm{~b}$ from $\mathrm{pEX}$ vector constructs (provided by Martine Bos, Utrecht University) and transformed into BL21 (DE3) cells. $\mathrm{Opa}_{60}$ was sub-cloned such that both $\mathrm{N}$ - and C-terminal fusion tags were included (MGSSHHHH HHSSGLVPRGSHM and KLAAALEHHHHHH, respectively) and $\mathrm{Opa}_{50}$ was sub-cloned to include only the N-terminal His-tag. Cells cultures were expressed in $\mathrm{D}_{2} \mathrm{O}(99.8 \%)$ minimal medium containing $4 \mathrm{~g} / \mathrm{l}^{13} \mathrm{C}(99 \%)$-glucose and $1 \mathrm{~g} /{ }^{15} \mathrm{~N}(99 \%)$-ammonium chloride (Cambridge Isotopes $\mathrm{Lab}$ ) at $310^{\circ} \mathrm{C}$ to an $\mathrm{OD}_{600}$ of $\approx 0.8$ then induced with $1 \mathrm{~m} M$ isopropyl$\beta$-thio-D-galactoside for $8 \mathrm{~h}$. The cells were resuspended and lysed in $50 \mathrm{~m} M$ Tris- $\mathrm{HCl}$ and $150 \mathrm{mM}$ $\mathrm{NaCl}$ (lysis buffer). The lysate was then centrifuged at $12,000 \mathrm{~g}$ for $30 \mathrm{~min}$. The pellet was resuspended in extraction buffer (lysis buffer with $8 M$ urea) and solubilized overnight. The resuspension was centrifuged at $12,000 \mathrm{~g}$ for $30 \mathrm{~min}$ and the supernatant was loaded onto a $\mathrm{Co}^{2+}$ immobilized metal affinity chromatography (IMAC) column equilibrated with 10 column volumes (CV) of extraction buffer. The column was then washed with $15 \mathrm{CV}$ of wash buffer ( $20 \mathrm{~m} M$ sodium phosphate, $\mathrm{pH} 7.8,150 \mathrm{mM} \mathrm{NaCl}$, $20 \mathrm{~m} M$ imidazole, $8 M$ urea) followed by an elution with $5 \mathrm{CV}$ of elution buffer $(20 \mathrm{~m} M$ sodium phosphate, $\mathrm{pH}$ 7.0, $150 \mathrm{mM} \mathrm{NaCl}, 680 \mathrm{~m} M$ imidazole).

\section{Refolding of $\mathrm{Opa}_{60}$ and $\mathrm{Opa}_{50}$}

The elution was concentrated to $200 \mu M$ and subsequently diluted 20 -fold with $20 \mathrm{~m} M$ Tris-HCl, $\mathrm{pH}$ 8.0, $500 \mathrm{~m} M \mathrm{NaCl}$ with $4.5 \mathrm{~m} M n$-dodecyl-phosphocholine (FC-12, Anatrace). The sample was incubated at room temperature for five days. Protein folding was monitored based on the shift of apparent molecular weight on SDS-PAGE, until the final sample lacked the higher apparent molecular weight band of the unfolded species. The solution was concentrated and dialyzed against $4 \mathrm{~L}$ of $20 \mathrm{mM}$ sodium phosphate, $\mathrm{pH} 6.2$, and $150 \mathrm{mM} \mathrm{NaCl}$; three times for an hour each. Final NMR samples were concentrated to $400-800 \mu M$ and contained $110-150 \mathrm{~m} M$ FC-12 as measured by comparing NMR peak intensities with standard FC-12 concentrations.

\section{Expression, purification, and refolding of OprH}

OprH expression plasmid was provided by Lukas Tamm (University of Virginia). Previously published protocols for expression, purification, and folding were followed. ${ }^{3}$ OprH was extracted in $50 \mathrm{mM}$ sodium phosphate, $\mathrm{pH} 8,300 \mathrm{~m} M \mathrm{NaCl}, 20 \mathrm{~m} M$ imidazole, and purified over a $\mathrm{Ni}^{2+}$ IMAC column with $15 \mathrm{CV}$ of wash buffer ( $50 \mathrm{mM}$ sodium phosphate, $\mathrm{pH}$ $8,300 \mathrm{~m} M \mathrm{NaCl}, 20 \mathrm{~m} M$ imidazole, and $8 M$ urea) followed by $5 \mathrm{CV}$ of elution buffer $(50 \mathrm{mM}$ sodium phosphate, $\mathrm{pH} 8.0,300 \mathrm{~m} M \mathrm{NaCl}, 250 \mathrm{~m} M$ imidazole, and $8 M$ urea). After purification, $\mathrm{OprH}$ was concentrated to $400 \mu M$ and diluted 10 -fold into OprH refolding buffer $(20 \mathrm{~m} M$ Tris-HCl, $\mathrm{pH}$ 8.5, $5 \mathrm{~m} M$ EDTA, $600 \mathrm{~m} M$ L-arginine with $3 \%$ 1,2-dihexanoyl-sn-glycero-3-phosphocholine (DHPC, Anatrace)) and incubated at $310^{\circ} \mathrm{C}$ for $72 \mathrm{~h}$. The diluted sample was concentrated and dialyzed against $2.5 \mathrm{~L}$ of $20 \mathrm{mM}$ Tris- $\mathrm{HCl}, \mathrm{pH} 8.5,5 \mathrm{mM}$ EDTA, and $50 \mathrm{~m} M \mathrm{KCl}$. The solution was then exchanged over a concentrator into sodium phosphate, $\mathrm{pH} 6.0,50 \mathrm{~m} M \mathrm{KCl}, 0.05 \%$ sodium azide for a final concentration of $600 \mu M$ OprH in $90 \mathrm{mM}$ DHPC. 


\section{Trypsin proteolysis}

Trypsin from porcine pancreas (Sigma-Aldrich) was added to the proteins in their respective final buffers at a trypsin:protein sample molar ratio between 1:50 and 1:100. After incubating overnight at room temperature, trypsin-treated samples were assessed with SDS-PAGE. SDS-PAGE samples were either boiled for 5 min or remained unboiled in SDS loading buffer and run alongside untreated samples both boiled and unboiled on 10\% Tris-HCl gels. Gels were stained with Coomassie brilliant blue. With confirmation of complete proteolysis from the SDS-PAGE gel, trypsin was removed by flowing the solution over $0.5 \mathrm{~mL}$ of $p$-aminobenzamidine-agarose resin (Sigma-Aldrich). The flow-through was then dialyzed against $4 \mathrm{~L}$ of $20 \mathrm{mM}$ sodium phosphate, $\mathrm{pH} 6.2$, and $150 \mathrm{mM} \mathrm{NaCl}$; three times for an hour each. Final NMR samples were concentrated to $400-800 \mu M$ and contained $110-150 \mathrm{mM}$ FC-12 as measured by comparing NMR peak intensities with standard FC-12 concentrations.

\section{Preparation of peptide}

A 20 amino acid peptide corresponding to a region in the third extracellular loop of $\mathrm{Opa}_{60}$ (AcTVPSNAPNGAVTTYNTDPKT-NH ${ }_{2}$ ) was synthesized by Anaspec with ${ }^{15} \mathrm{~N}$ amide nitrogen incorporation for all threonine, valine, alanine, and lysine residues. The lyophilized peptide was resuspended in $20 \mathrm{~m} M$ sodium phosphate, $\mathrm{pH} 6.2$, and $150 \mathrm{mM} \mathrm{NaCl}$ at a concentration of $1.0 \mathrm{mM}$.

\section{NMR spectroscopy}

NMR spectra were collected on Bruker AVANCE spectrometers operating at proton frequencies of 600 $\mathrm{MHz}$ and $800 \mathrm{MHz}$ equipped with Bruker $5 \mathrm{~mm}$ TXI cryoprobes and recorded at $10,20,30$, and $40^{\circ} \mathrm{C}$ for $\mathrm{Opa}_{60}$ and the synthetic peptide, $40^{\circ} \mathrm{C}$ for $\mathrm{Opa}_{50}$, and $45^{\circ} \mathrm{C}$ for $\mathrm{OprH}$. Spectra were processed with Topspin and assigned using CARA. ${ }^{29}$ In order to assign the backbone, TROSY versions of HNCA, $\mathrm{HN}(\mathrm{CO}) \mathrm{CA}, \mathrm{HNCO}, \mathrm{HN}(\mathrm{CA}) \mathrm{CO}, \mathrm{HN}(\mathrm{CA}) \mathrm{CB}$, and $\mathrm{HN}(\mathrm{COCA}) \mathrm{CB}$ pulse sequences were recorded for both the full-length and trypsin-treated samples. ${ }^{15} \mathrm{~N},{ }^{1} \mathrm{H}$ TROSY-HSQC spectra were recorded over a series of temperatures from $40^{\circ} \mathrm{C}$ to $10^{\circ} \mathrm{C}$ to observe chemical shifts changes of assigned resonances for both $\mathrm{Opa}_{60}$ and the synthetic peptide. $2 \mathrm{D}{ }^{1} \mathrm{H},{ }^{1} \mathrm{H}$ TOCSY, and COSY spectra and ${ }^{15} \mathrm{~N}$-edited versions of each were recorded for the peptide to assign the side chains.

\section{Acknowledgments}

Authors thank Jeff Ellena for providing NMR technical support; Lukas Tamm for providing the OprH plasmid; and Iga Kucharska for providing helpful discussion for the preparation of OprH; Ryan Lo and Ashton Brock proofread and edited the manuscript.

\section{References}

1. Hwang PM, Choy WY, Lo EI, Chen L, Forman-Kay JD, Raetz CR, Prive GG, Bishop RE, Kay LE (2002) Solution structure and dynamics of the outer membrane enzyme PagP by NMR. Proc Natl Acad Sci USA 99: 13560-13565.

2. Hiller S, Garces RG, Malia TJ, Orekhov VY, Colombini M, Wagner G (2008) Solution structure of the integral human membrane protein VDAC-1 in detergent micelles. Science 321:1206-1210.

3. Edrington TC, Kintz E, Goldberg JB, Tamm LK (2011) Structural basis for the interaction of lipopolysaccharide with outer membrane protein $\mathrm{H}(\mathrm{OprH})$ from Pseudomonas aeruginosa. J Biol Chem 286:39211-39223.

4. Arora A, Abildgaard F, Bushweller JH, Tamm LK (2001) Structure of outer membrane protein A transmembrane domain by NMR spectroscopy. Nat Struct Biol 8:334-338.

5. Liang B, Tamm LK (2007) Structure of outer membrane protein G by solution NMR spectroscopy. Proc Natl Acad Sci USA 104:16140-16145.

6. Fernandez C, Adeishvili K, Wuthrich K (2001) Transverse relaxation-optimized NMR spectroscopy with the outer membrane protein OmpX in dihexanoyl phosphatidylcholine micelles. Proc Natl Acad Sci USA 98: 2358-2363.

7. Subbarao GV, van den Berg B (2006) Crystal structure of the monomeric porin OmpG. J Mol Biol 360: 750-759.

8. Pautsch A, Schulz GE (2000) High-resolution structure of the OmpA membrane domain. J Mol Biol 298: 273-282.

9. Ahn VE, Lo EI, Engel CK, Chen L, Hwang PM, Kay LE, Bishop RE, Prive GG (2004) A hydrocarbon ruler measures palmitate in the enzymatic acylation of endotoxin. EMBO J 23:2931-2941.

10. Bayrhuber M, Meins T, Habeck M, Becker S, Giller K, Villinger S, Vonrhein C, Griesinger C, Zweckstetter M, Zeth K (2008) Structure of the human voltagedependent anion channel. Proc Natl Acad Sci USA 105: 15370-15375.

11. Yildiz O, Vinothkumar KR, Goswami P, Kuhlbrandt W (2006) Structure of the monomeric outer-membrane porin OmpG in the open and closed conformation. EMBO J 25:3702-3713.

12. Vogt J, Schulz GE (1999) The structure of the outer membrane protein OmpX from Escherichia coli reveals possible mechanisms of virulence. Structure 7: 1301-1309.

13. Grzesiek S, Anglister J, Ren H, Bax A (1993) C-13 line narrowing by $\mathrm{H}-2$ decoupling in $\mathrm{H}-2 / \mathrm{C}-13 / \mathrm{N}-15$ enriched proteins-application to triple-resonance $4 \mathrm{~d}$ Jconnectivity of sequential amides. J Am Chem Soc 115: 4369-4370.

14. Pervushin K, Riek R, Wider G, Wuthrich K (1997) Attenuated T-2 relaxation by mutual cancellation of dipole-dipole coupling and chemical shift anisotropy indicates an avenue to NMR structures of very large biological macromolecules in solution. Proc Natl Acad Sci USA 94:12366-12371.

15. Waugh DS (1996) Genetic tools for selective labeling of proteins with alpha-N-15-amino acids. J Biomol NMR 8:184-192. 
16. Zhuang TD, Vishnivetskiy SA, Gurevich VV, Sanders CR (2010) Elucidation of inositol hexaphosphate and heparin interaction sites and conformational changes in arrestin-1 by solution nuclear magnetic resonance. Biochemistry 49:10473-10485.

17. Reckel S, Sobhanifar S, Schneider B, Junge F, Schwarz D, Durst F, Lohr F, Guntert P, Bernhard F, Dotsch V (2008) Transmembrane segment enhanced labeling as a tool for the backbone assignment of alpha-helical membrane proteins. Proc Natl Acad Sci USA 105: 8262-8267.

18. Tugarinov V, Kay LE (2003) Ile, Leu, and Val methyl assignments of the 723-residue malate synthase G using a new labeling strategy and novel NMR methods. J Am Chem Soc 125:13868-13878.

19. Goto NK, Gardner KH, Mueller GA, Willis RC, Kay LE (1999) A robust and cost-effective method for the production of Val, Leu, Ile (delta 1) methyl-protonated 15N-, 13C-, 2H-labeled proteins. J Biomol NMR 13: 369-374.

20. Cierpicki T, Liang B, Tamm LK, Bushweller JH (2006) Increasing the accuracy of solution NMR structures of membrane proteins by application of residual dipolar couplings. High-resolution structure of outer membrane protein A. J Am Chem Soc 128:6947-6951.

21. Klammt C, Maslennikov I, Bayrhuber M, Eichmann C, Vajpai N, Chiu EJ, Blain KY, Esquivies L, Kwon JH, Balana B, Pieper U, Sali A, Slesinger PA, Kwiatkowski W, Riek R, Choe S (2012) Facile backbone structure determination of human membrane proteins by NMR spectroscopy. Nat Methods 9:834-839.
22. Bhat KS, Gibbs CP, Barrera O, Morrison SG, Jahnig F, Stern A, Kupsch EM, Meyer TF, Swanson J (1991) The opacity proteins of Neisseria gonorrhoeae strain MS11 are encoded by a family of 11 complete genes. Mol Microbiol 5:1889-1901.

23. Malorny B, Morelli G, Kusecek B, Kolberg J, Achtman M (1998) Sequence diversity, predicted two-dimensional protein structure, and epitope mapping of neisserial Opa proteins. J Bacteriol 180:1323-1330.

24. Schweizer M, Hindennach I, Garten W, Henning U (1978) Major proteins of Escherichia coli outer cellenvelope membrane-interaction of protein-Iistar with lipopolysaccharide. Eur J Biochem 82:211-217.

25. Szymczyna BR, Gan L, Johnson JE, Williamson JR (2007) Solution NMR studies of the maturation intermediates of a $13 \mathrm{MDa}$ viral capsid. J Am Chem Soc 129:7867-7876.

26. Hauck CR, Meyer TF (2003) 'Small' talk: Opa proteins as mediators of Neisseria-host-cell communication. Curr Opin Microbiol 6:43-49.

27. Kyte J, Doolittle RF (1982) A simple method for displaying the hydropathic character of a protein. J Mol Biol 157:105-132.

28. Dewald AH, Hodges JC, Columbus L (2011) Physical determinants of beta-barrel membrane protein folding in lipid vesicles. Biophys J 100:2131-2140.

29. Keller RLJ (2004) Optimizing the process of nuclear magnetic resonance spectrum analysis and computer aided resonance assignment. Swiss Federal Institute of Technology Zurich, Zurich. 